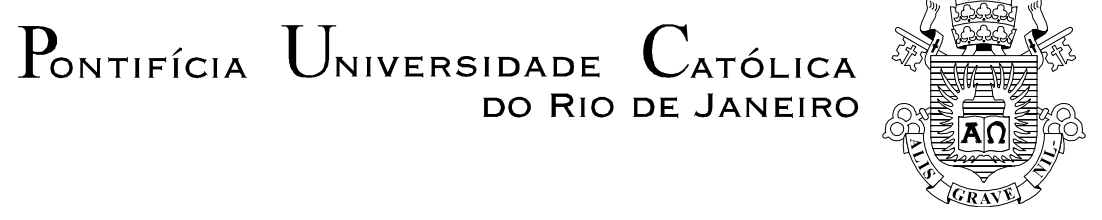

Letícia da Costa Paes

A Política dos Direitos Humanos
Entre Paradoxos e Perspectivas

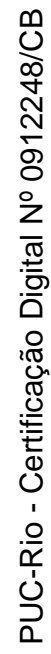

Dissertação de Mestrado

Dissertação apresentada ao Programa de PósGraduação em Direito da PUC-Rio como requisito parcial para obtenção do título de Mestre em Direito.

Orientadora: Prof ${ }^{\mathrm{a}}$. Bethânia de Albuquerque Assy

Rio de Janeiro Agosto de 2011. 


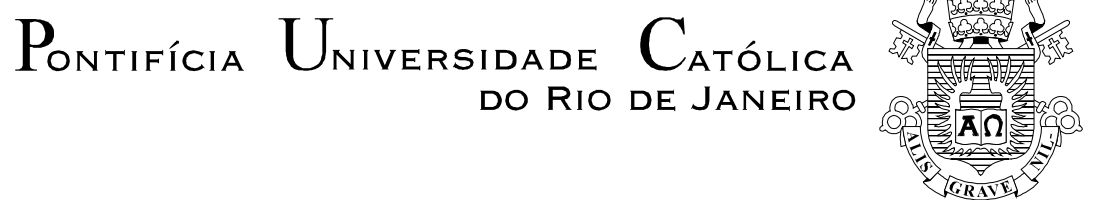

Letícia da Costa Paes

\section{A Política dos Direitos Humanos Entre Paradoxos e Perspectivas}

Dissertação apresentada ao Programa de PósGraduação em Direito da PUC-Rio como requisito parcial para obtenção do título de Mestre em Direito. Aprovada pela Comissão Examinadora abaixo assinada.

Prof ${ }^{a}$ Bethânia de Albuquerque Assy

Orientadora

Departamento de Direito - PUC-Rio

Prof. Adriano Pilatti

Co-orientador

Departamento de Direito - PUC-Rio

Prof. Francisco de Guimaraens

Departamento de Direito - PUC-Rio

Prof. José Ricardo Ferreira Cunha

Fundação Getúlio Vargas - RJ

Profá. Mônica Herz

Vice-Decana de Pós-Graduação do Centro de

Ciências Sociais - PUC-Rio

Rio de Janeiro, 05 de agosto de 2011. 
Todos os direitos reservados. É proibida a reprodução total ou parcial do trabalho sem autorização da universidade, da autora e do orientador.

\section{Letícia da Costa Paes}

Bacharel em Direito pela Pontifícia Universidade Católica do Rio de Janeiro (2008). Bolsista da FAPERJ (Programa Bolsa Nota 10) e do CNPQ durante o mestrado. Desenvolveu pesquisas e coordenou estudos sobre o Sistema Interamericano de Proteção dos Direitos Humanos.

Ficha Catalográfica

Paes, Letícia da Costa.

A Política dos Direitos Humanos: Entre Paradoxos e Perspectivas / Letícia da Costa Paes; Orientadora: Bethânia de Albuquerque Assy - Rio de Janeiro: PUC, Departamento de Direito, 2011.

135 f. ; $30 \mathrm{~cm}$

Dissertação (mestrado) - Pontifícia Universidade Católica do Rio de Janeiro, Departamento de Direito.

Inclui referências bibliográficas.

1. Direito - teses. 2. Direitos Humanos. 3. política. 4. ação. 5. dissenso. I. Assy, Bethânia de Albuquerque. II. Pontifícia Universidade Católica do Rio de Janeiro. Departamento de Direito. III. Título.

CDD: 340 


\section{Agradecimentos}

Ao CNPq, à CAPES e à PUC-Rio, pelos auxílios concedidos, sem os quais este trabalho não teria sido realizado;

À professora Bethania, pela orientação, pela gentileza desde os tempos da graduação, por tornar a minha compreensão sobre os direitos humanos mais estimulante e por me acolher nos momentos mais angustiantes desse processo;

Ao professor Adriano Pilatti não só pela orientação, mas pela sensibilidade e pela confiança. Se hoje eu entendo os direitos a partir de uma perspectiva constituinte, a culpa é toda dele;

Aos professores e amigos do Núcleo dos Direitos Humanos, por despertarem o meu interesse no Direito e criarem um espaço de criatividade e liberdade. Agradeço, especialmente, à professora Carolina de Campos Melo, pelos incentivos e aposta em meu trabalho. Ainda, à ela, Márcia Nina, Daniela Vargas e Rachel Herdy por me confiarem o cargo de coach e pela possibilidade de conduzir os encontros do grupo simulações e realidade;

Aos professores Francisco de Guimaraens e Mauricio Rocha, pelos ensinamentos e encontros spinozistas;

A todos os professores do Departamento de Direito pelos ensinamentos, em especial à professora Gisele Cittadino;

A todos os funcionários do departamento de Direito, em especial ao Anderson, pela ajuda e por tornar mais leve a minha vida de mestranda;

À amiga Priscila Santana, por transbordar afeto e ser minha companheira inseparável na alegria e nas neuroses de ser mestranda;

As amigas (os) do Núcleo de Direitos Humanos, Fernanda, Luiza, Andrea, Pilar, Cecília, Tereza, Isabella, Fábio, pelos bons tumultos, sem os quais tudo seria mais entediante;

Ao Gustavo, por te lido esse trabalho e mostrar interesse pelas coisas que eu acredito. Tive sorte em conhecê -lo e guardo o desejo que permaneça em minha vida. Todo o resto não cabe aqui. Espero que saibas.

Aos meus pais pelo carinho, compreensão e apoio;

Ao Beto, Monique, Rodrigo e Carlitos, pela presença especial em minha vida;

As mais importantes de todas, a família que escolhi: Lulu, por compartilhar comigo os desafios de enfrentar "esse" mundo e, sobretudo, pelo enorme afeto e apoio do dia-a-dia. Pri, pelo carinho constante e por essa capacidade rara de escutar o outro. Pat, por me lembrar todos os dias que só o amor importa; Tita, pela alegria pulsante sem a qual teria muito mais dificuldade em continuar. Barbara, por me arrancar da obviedade. 


\section{Resumo}

Paes, Letícia da Costa; Assy, Bethânia de Albuquerque. A Política dos Direitos Humanos: Entre Paradoxos e Perspectivas. Rio de Janeiro, 2011. 135p. Dissertação de Mestrado - Departamento de Direito, Pontifícia Universidade Católica do Rio de Janeiro.

A pesquisa pretende desafiar o atual princípio organizador dos direitos humanos, demonstrar suas contradições e repensá-los a partir de uma nova perspectiva, de modo a resgatar a política ativa destes direitos. Para isso, esse trabalho foi dividido em três partes. A primeira aborda os paradoxos que perpassam a teoria e prática dos direitos humanos, a partir das obras do jurista grego Costas Douzinas. A segunda analisa as tradicionais críticas dos direitos humanos, elaboradas por Burke, Marx e Arendt, que contribuem para compreender os fundamentos de suas contradições. A terceira visa estabelecer uma nova perspectiva sobre os direitos humanos, a partir das reflexões de Jacques Rancière.

\section{Palavras-chave}

Direitos Humanos; política; ação; dissenso. 


\section{Abstract}

Paes, Letícia da Costa; Assy, Bethânia de Albuquerque (Advisor). The Policy Of Human Rights: Between Paradox And Perspective. Rio de Janeiro, 2011. 135p. MSc. Dissertation - Departamento de Direito, Pontifícia Universidade Católica do Rio de Janeiro.

The purpose of this work is challenging the current human rights framework, demonstrating its contradictions, as well as rethinking it under a new perspective, in a manner to reactivate the political struggle of those rights. For this purpose, this work has been split into three different sections. The first one presents the paradoxes between the theory and practice of human rights, having as main reference the thoughts of the Greek legal scholar Costas Douzinas. The second section examines the critics posed by Burke, Marx and Arendt to the traditional human rights theory, thereby clarifying the foundations of its contradictions. The third section aims at establishing a new human rights perspective, in light of Jaques Rancière thinking.

\section{Keywords}

Human rights; politics; action; dissensus. 


\section{SUMÁRIO}

$\begin{array}{ll}\text { Introdução } & 9\end{array}$

1. Os paradoxos dos direitos humanos $\quad 14$

1.1 - Humanidade para quem? 15

1.2 - Estado e direitos humanos: uma relação impotente 21

1.3 As promessa fracassada dos direitos humanos: liberdade no contexto 31 biopolítico

1.4 As intervenções humanitárias como projeto político 36

1.5 A despolitização da política 52

2. As críticas tradicionais aos direitos humanos 60

2.1 A ilusão dos direitos humanos: Edmund Burke 60

2.2 A ideologia burguesa e os Direitos Humanos: Karl Marx 67

2.3 Ruptura entre cidadão e homem: Hannah Arendt 77

3. Trançando novas perspectivas 95

3.1 A política do dissenso 95

3.2 O Sujeito dos direitos Humanos 103

3.3 A política dos Direitos Humanos 113

4. Conclusão 124

$\begin{array}{lr}\text { 5. Referências Bibliográficas } & 130\end{array}$ 
Caminante, no hay camino, se hace camino al andar

Antonio Machato 